\title{
EL DISCURSO DELIRANTE DE PHĖDRE EN LA SEXTA ESCENA DEL ACTO IV: UNA CONFESIÓN FRUSTRADA Y CUATRO JUICIOS
}

\author{
Cristina Fernández Lacueva \\ Universidad Complutense \\ Madrid, España \\ cristina.fernandez.lacueva@gmail.com
}

\section{RESUMEN / ABSTRACT}

En la sexta escena del acto IV de Phèdre de Jean Racine, los celos llevan a la heroína a renunciar a la confesión que iba a hacerle a Thésée para ayudar a Hippolyte. El "furor erótico" de Phèdre deviene un "furor poético" donde la confesión frustrada es sustituida por un soliloquio delirante en tres tiempos en el que culpa a Aricie (1), se culpa a sí misma (2) y, finalmente, culpa a los dioses, a Enone y a su estirpe (3) por sus propios crímenes. En el plano formal, estos cambios se plasman en la "estructura judicial" de la escena, constituida por cuatro juicios simbólicos que reflejan los diversos estadios del discurso de Phèdre.

PALABRAS Clave: Racine, derecho, narcisismo, psicoanálisis, verborrea.

\section{PHÈDRE'S DELIRIOUS DISCOURSE IN THE SIXTH SCENE OF THE ACT IV: ONE FRUSTRATED CONFESSION AND FOUR TRIALS}

In the sixth scene of the act IV of Racine's Phèdre, jealousy forces the heroine to give up on the confession she was going to make to Thésée in order to help Hippolyte. Nevertheless, Phèdre's "erotic furor" becomes a "poetic furor" and the frustrated confession is replaced by a delirious soliloquy in three times in which she blames Aricie (1), blames herself (2), and, finally, blames the gods, Enone and even her line (3) for her own crimes. Those changes are formally reflected on the "judicial structure", constituted by four symbolic trials which reflect the different phases of Phèdre's discourse.

KEYWORDS: Racine, law, narcissism, psychoanalysis, verbosity. 


\section{INTRODUCCIÓN: EL DIÁLOGO ENTRE TRAGEDIA Y DERECHO}

Phèdre ocupa un lugar central no solo en la obra de Racine (1639-1699), sino en el género trágico en su totalidad, desde la tradición clásica hasta la contemporaneidad. Racine, que escribe entonces desde su privilegiada posición de historiógrafo del rey durante el reinado de Luis XIV -un momento de gran florecimiento intelectual que comparte con Molière, Corneille, La Fontaine, Pascal, La Bruyère, Descartes o La Rochefoucauld, entre muchos otros-, alcanzó con Phèdre (1677) "el grado máximo de perfección de su concepto de tragedia, [...] haciendo de ella la síntesis ideal" (Náñez 27). En efecto, Phèdre condensa todos los elementos fundamentales de la tragedia clásica -la hamartia, el acto del héroe que desencadena su infortunio; la hibris y el pathos, el orgullo y el sufrimiento que lo caracterizan, y la catarsis final (Pavis 487)-, a los que se suma la profundidad psicológica que singulariza a los personajes racinianos, en los que se hace evidente la educación jansenista que recibió el autor desde los cuatro años, cuando fue puesto al cuidado de las religiosas de Port-Royal, debido a la pronta muerte de sus padres. A pesar de que, como veremos, la mayor parte del peso trágico de la obra recae en Phèdre, el resto de los personajes no son "meros comparsas", sino que constituyen un entramado interrelacional de una gran complejidad en cuyo centro se encuentra, efectivamente, la protagonista, que se construye a partir de "un progresivo buceo en sí misma", de un "despeñarse en las insondables cimas del yo" (Náñez 41). El mito, bien conocido por los lectores, narra la historia de la princesa cretense Fedra, hija de Minos y Pasífae y hermana de Ariadna, que se enamora de Hipólito, hijo de su marido, Teseo, y de una amazona. El amor desenfrenado que lleva a Fedra al borde de la locura es, en realidad, un acto de venganza de Afrodita hacia Hipólito por haberla despreciado y haber rendido culto únicamente a Artemisa. Racine introduce algunos cambios muy interesantes -desde modificaciones en la psicología de los personajes hasta personajes nuevos, como veremos posteriormente con mayor detenimiento-, pero existe un amplio consenso entre los especialistas en su obra en que quizás lo más valioso de su versión del mito sea la construcción lingüística del efecto trágico que, como trataremos de demostrar en el presente artículo, a partir del análisis de la sexta escena del acto IV, no depende únicamente de las confesiones, sino también -y quizás de forma más profunda- de los silencios.

Después del destierro de Hippolyte, Phèdre se dispone a confesar ante Thésée la verdad: fue ella quien intentó seducir a Hippolyte y no al revés. Sin embargo, justo antes de hacerlo, Thésée le desvela a Phèdre el argumento 
utilizado por Hippolyte para defenderse de la acusación emitida por Enone: su amor por Aricie. Esta es la situación que precede a la sexta escena del acto IV, que supone un punto de inflexión en el desarrollo de la obra, puesto que la declaración de Thésée desata los celos de Phèdre y esto, a su vez, provoca una desviación de su palabra: la confesión que iba a hacerle a Thésée es sustituida por un soliloquio ante Enone en el que el discurso de Phèdre se caracteriza por su verborrea. Los celos, por tanto, como señalan Mathé y Couprie, desempeñan un rol decisivo en el desarrollo de la tragedia: "Phèdre se convierte en su propio verdugo, se recrea en imágenes que la hieren. Los celos agravan su sufrimiento" $(36)^{1}$. La confesión que Phèdre iba a llevar a cabo se presenta entonces como una verdadera insensatez: "Qui sait même où m'allait porter ce repentir ? / Peut-être à m'accuser j'aurais pu consentir; / Peut-être, si la voix ne m'eût été coupée, / L'affreuse vérité me serait échappée" ["¿Quién sabe hasta dónde habría llegado en mi arrepentimiento? / Quizá incluso hasta acusarme, / si la voz no me hubiera fallado. / Tal vez se me habría escapado la temible verdad"] (1199-1202)2. Aunque los celos son el punto de partida del flujo discursivo casi inconsciente que domina a Phèdre -lo admite ella misma cuando hace referencia a "ma jalouse rage" ["mi rabia celosa"] (1258) y a "mes jaloux transports" ["mis transportes celosos"] (1263)-, hay otro factor clave que influye en la decisión de romper su silencio: el impulso que le da Enone, que, como bien apunta Barthes en su célebre ensayo sobre Racine, desempeña el papel de nodriza también en el ámbito lingüístico, pues consigue extraer de Phèdre la palabra oculta, sacar el lenguaje "de la profunda fosa en que está sumido", de modo que la obra deviene una "tragedia del alumbramiento" (150). Dos intervenciones de CEnone aparentemente irrelevantes -“Aricie?" (transición al verso 1225) y "Quel fruit recevront-ils de leurs vaines amours ? / Ils ne se verront plus" [“¿Qué fruto producirán sus vanos amores? / Nunca más se verán”] (1251-1252)- se convertirán, como veremos a continuación, en el impulso necesario para que Phèdre transforme sus emociones en lo que será un verdadero soliloquio ${ }^{3}$.

La traducción es nuestra.

En el caso de las citas de Phèdre, haremos constar, entre paréntesis, los versos correspondientes a la edición francesa que consignamos en la Bibliografía. Asimismo, entre corchetes, incluiremos la traducción de los versos en cuestión al español de M. ${ }^{a}$ Dolores Fernández Lladó, también presente en la bibliografía.

A pesar de que técnicamente sea un diálogo entre Phèdre y Enone, a menudo nos referiremos a las intervenciones de la protagonista con el término "soliloquio", puesto que, 
Como anunciábamos al principio, a través de la interpretación de la escena que proponemos en el presente artículo, trataremos de demostrar que la frustración de la confesión de Phèdre ante Thésée no implica necesariamente un fracaso del desarrollo del sentido trágico, sino que, por el contrario, constituye una de sus máximas expresiones. En este sentido, deviene fundamental el concepto de "tragedia nominalista" con que Barthes caracteriza Phèdre: mientras que las confesiones de la protagonista acercan progresivamente a la tragedia a su desenlace, el silencio contribuye a su perpetuación, puesto que es lo único que la mantiene viva. Dicho de otro modo, Phèdre "se sabe culpable, pero no es su culpabilidad lo que constituye el problema sino su silencio" (147). Desde esta premisa, en la escena en cuestión, el silencio de Phèdre revela un carácter radicalmente trágico, pues no se trata de un silencio pasivo, adoptado por conveniencia o comodidad, sino de un silencio activo que Phèdre se impone a sí misma por orgullo -recordemos que acaba de descubrir que Hippolyte está enamorado de Aricie-, pero que no responde a un deseo real de permanecer callada, sino todo lo contrario. A raíz del trasiego emocional sufrido, Phèdre necesita hablar, pero, en lugar de satisfacer esta necesidad confesándose ante Thésée, emprende una confesión inconsciente de los sentimientos que hasta entonces se esforzaba por ocultar ante una Enone que, fruto del estado de enajenación en el que se encuentra Phèdre, parece haber desaparecido y que, en cierto modo, encarna la figura del espectador-lector.

Esta escena destaca también por su composición formal y, más concretamente, por su peculiar estructura. El núcleo del discurso de Phèdre (versos 12271297) está conformado por tres partes diferenciadas correspondientes a tres "juicios simbólicos", a su vez determinados por los tres estados anímicos por los que pasa Phèdre, esto es, el furor, la culpabilidad y la autocompasión -que corresponden respectivamente a los versos 1225-1263, 1264-1273 y 1273-1294-. Hacia el final de la escena, se produce nuevamente un diálogo entre Phèdre y Enone en el que se desarrolla lo que podríamos considerar como un cuarto juicio simbólico, fuera ya del soliloquio propiamente. Así pues, la "estructura judicial" constituye el principal elemento formal utilizado por Racine para revelar las causas de los cambios en el comportamiento de Phèdre, puesto que, en función del sentimiento predominante en cada parte de

como veremos, parece hablar consigo misma, y porque su parlamento presenta una consistencia discursiva así como una dimensión moral y psicológica que lo distinguen de un monólogo común (Pavis 430). 
su discurso, se producen modificaciones en los factores esenciales del juicio: cambian los agentes que intervienen en él, así como el motivo de la acusación, la resolución y el tono. En una primera lectura, ya advertimos la aparición reiterada de términos y expresiones del campo semántico jurídico -tales como "crimen", "incesto", "fraude", "manos homicidas", "linaje inocente", "urna", "verdugo", "venganza", "juzgar" o "confesar", entre otros-. En realidad, el evidente peso en la escena del derecho, en tanto que disciplina reguladora de la conducta humana mediante un sistema eminentemente lingüístico como son las leyes, es una consecuencia natural del carácter performativo que adquiere la palabra en la obra. Como señala Barthes, "la conducta del héroe raciniano es esencialmente verbal" (96), de modo que los actos son sustituidos por su enunciación: decir es hacer.

Asimismo, el carácter frenético y prácticamente inconsciente que presenta la palabra en esta escena requiere no solo de una lectura que vincule a la tragedia con el derecho, sino también de una interpretación de corte psicoanalítico. De hecho, esta perspectiva sobre Phèdre ya ha sido adoptada por varios especialistas -entre ellos, Mauron, Barthes, Spitzer, Orlando y Mathé y Couprie-, cuyos estudios han servido como base fundamental del presente artículo y, en realidad, no sorprende que así sea, dada la estrecha relación entre la tragedia y el psicoanálisis que puso de relieve el propio Freud ${ }^{4}$.

\section{PRIMER JUICIO: LA CONDENA DE ARICIE}

La relación amorosa entre Hippolyte y Aricie es una de las innovaciones introducidas por Racine con la intención de añadir al personaje de Hippolyte una "debilidad que le hiciese un poco culpable respecto a su padre" (Racine, Fedra 150). Sin embargo, la introducción de Aricie no solo aporta complejidad a la construcción psicológica de Hippolyte, sino también a la de Phèdre. Si bien es cierto que Phèdre ya sentía una atracción por Hippolyte, en cuanto advierte la existencia de una rival -es la propia Phèdre quien la concibe

\footnotetext{
Piglia describe dicha relación con gran acierto: "El psicoanálisis nos convoca a todos como sujetos trágicos; nos dice que hay un lugar en el que somos sujetos extraordinarios, tenemos deseos extraordinarios, luchamos contra tensiones y dramas profundísimos, y esto es muy atractivo. De modo que el psicoanálisis, como bien dice Freud, genera resistencia y es un arte de la resistencia y de la negociación, pero también es un arte de la guerra y de la representación teatral, intensa y única" (58-59).
} 
abiertamente como tal: "EEnone, qui l'eût cru ? J'avais une rivale !" ["Enone, ¿quién lo hubiera creído? / Tenía una rival”] (1218)-, su pasión adquiere tintes mucho más bruscos. Podríamos explicar este fenómeno mediante la teoría del deseo mimético de Girard (6), por la cual Aricie ocuparía el rol de mediadora, cumpliendo una doble función: en tanto que modelo, ayudaría a Phèdre no solo a dirigir su deseo hacia un objeto concreto -Hippolyte-, sino también a imaginar de forma más precisa su fantasía después de verla realizada en los otros; en tanto que rival, despertaría en Phèdre los celos que la llevan ese estado de furor extremo que muestra el aspecto más destructivo de la pasión amorosa. También es interesante la reflexión que hace Girard en relación con los celos, sentimiento omnipresente en el parlamento de Phèdre: el celoso trata de autoconvencerse de que su deseo es espontáneo y previo a la intervención del mediador, concebido entonces como "un intruso, un estorbo, un terzo incommodo que acude a interrumpir un delicioso têteà-tête" (Girard 18). En efecto, los celos no son ajenos a la mediación, sino que, por el contrario, constituyen su expresión más evidente, en tanto que el temperamento celoso revela, en el fondo, "una irresistible propensión a desear lo que desean los Otros, es decir, a imitar sus deseos" (ibid.). En suma, la introducción de la mediación a través del personaje de Aricie provoca la aparición de los celos de Phèdre, cuya influencia se manifiesta principalmente en el sentimiento que la domina en la primera parte.

Dicho sentimiento es el furor. Es la propia Phèdre quien pronuncia en dos ocasiones la palabra fureur -"La fureur de mes feux, l'horreur de mes remords, / Et d'un cruel refus l'insupportable injure, / N'était qu'un faible essai du tourment que j'endure" ["el furor de mi pasión, el horror de mis remordimientos, / y la insoportable injuria de un rechazo cruel, / no eran más que un débil preludio del tormento que padezco"] (1228-1230); y refiriéndose a Hippolyte y Aricie: "Ils bravent la fureur d'une amante insensée" [“ellos desafían la furia de una mente insensata"] (1254) -, un término muy polisémico que, en este contexto, comprende la mayoría de sus acepciones: "locura que lleva a actos de violencia", "pasión sin medida", "cólera insensata" (Grand Robert). Como bien observa Louise Frappier, aunque el término propiamente proviene del latín furor, definido por Cicerón como un "exceso de bilis negra" -el mismo movimiento que Aristóteles advierte en la "melancolía"-, se ha equiparado a menudo al concepto platónico de "manía", que presenta una doble vertiente: en su vertiente negativa, se trata de una enfermedad derivada del exceso de placeres y dolores; en su vertiente positiva, tiene un origen divino y se manifiesta principalmente en el amor y en la poesía (32). Esta 
última vertiente de la "manía" podría vincularse a la expresión "furor poético" -equivalente al furor loquendi latino-, que hace referencia -sublimándoloal fenómeno de la verborrea. En este sentido, Phèdre transforma su furor erótico en un furor verbal, puesto que, recuperando la hipótesis de Barthes, la conducta del héroe raciniano es esencialmente lingüística ${ }^{5}$.

Así pues, sabemos cómo se origina el furor "erótico" de Phèdre -a partir de la mediación interna de Aricie y de los subsiguientes celos-, de modo que ahora debemos tratar de comprender cómo este se transforma en un furor "poético". Al principio, Phèdre tan solo explica a Enone que Hippolyte ama, pero finalmente decide confesar también a quién ama: a Aricie $^{6}$. (Enone queda tan (aparentemente) impactada que no puede más que repetir el nombre mediante una pregunta retórica: “Aricie ?" (1225). Esta breve intervención no contribuye a la dinámica propia del diálogo -desde el punto de vista del contenido, no aporta ninguna información significativa, sino que tan solo invierte la lógica del intercambio dialógico-, pero actúa como el "elemento dado" que posibilita el desarrollo, por parte de Phèdre, de un discurso basado en lo que, en psicoanálisis, se ha denominado "regla de la asociación libre" y, por ende, de un discurso que en muchos momentos parece ser completamente inconsciente ${ }^{7}$. Asimismo, debemos advertir que entre Phèdre y Enone se produce el fenómeno de la identificación: en su primera intervención, Enone parece saber lo que Phèdre ha de decirle, pues habría somatizado unos celos que, por otra parte, no le pertenecen; de ahí que el impacto que le produce la confesión de Phèdre sea tan solo aparente ${ }^{8}$. Por

5 También cabe destacar que el concepto de "furor uterino", una de las denominaciones de la hipersexualidad (Moliner 1416), encajaría con el exceso libidinal de Phèdre.

6 Como advierte Barthes, el amor es intransitivo por naturaleza, puesto que "carece de objeto: yo amo, yo amaba, vosotros amáis, es preciso que finalmente yo ame" (89). Sin ir más lejos, al final de esta escena, CEnone dice: "Vous aimez" [“Amáis”] (1297). En cierto sentido, podríamos vincular la intransitividad del verbo con el deseo mimético girardiano: el objeto de deseo está en constante movimiento, pues depende siempre del mediador; lo que se mantiene intacto siempre es el acto de desear, el deseo mismo.

En psicoanálisis la "asociación libre" es el método consistente en "expresar sin discriminación todos los pensamientos que vienen a la mente, ya sea a partir de un elemento dado (palabra, número, imagen de un sueño, representación cualquiera), ya sea de forma espontánea" (Laplanche y Pontalis 35).

En realidad, es la misma Phèdre quien advierte que CEnone ya era conocedora de la relación de Hippolyte y Aricie: "Tu le savais. Pourquoi me laissais-tu séduire ? / De leur furtive ardeur ne pouvais-tu m’instruire ?" [“Tú lo sabías. ¿Por qué me dejabas seguir en el engaño? / ¿No podías haberme informado de su furtivo amor?’] (1233-1234). 
esta razón, podríamos concebir a Enone como un doble de Phèdre que no solo sabe lo mismo que ella sin necesidad de verbalizarlo, sino que también siente lo mismo, incluso en el plano físico - Enone tiembla y palidece (12201221) - lo que reforzaría la concepción del texto como un soliloquio, más que como un verdadero diálogo.

En esta primera parte, Phèdre emplea un tono extremadamente agresivo, de modo que, en el juicio simbólico, adopta el rol de denunciante y coloca a Aricie en el de acusada debido a su relación con Hippolyte. La posición de Phèdre está clara: "Il faut perdre Aricie" ["Hay que perder a Aricia"] (1259). El uso de la construcción "il faut" es una prueba del furor que la domina, puesto que implica no solo una obligación, sino sobre todo una necesidad: la muerte de Aricie deviene la única condición para que Phèdre siga viviendo, puesto que los celos son mortales para ella -imaginar a los dos amantes constituye una "mortelle pensée" ["pensamiento mortal"] (1253)- y Aricie es su causante. Sin embargo, Phèdre es consciente de que para condenar a Aricie es necesaria la aprobación de una figura de autoridad. De ahí que acuda a Thésée, quien, por consiguiente, adquiere el rol de juez: "il faut de mon époux / contre un sang odieux réveiller le courroux" ["La cólera de mi esposo / debe ser azuzada contra su odiosa estirpe"] (1259-1260). La enemistad con Aricie llega a tal extremo que Phèdre es capaz de dejar de lado el rencor que siente hacia Thésée -que no solo se revela en la decisión de ponerle al mismo nivel que Aricie en el verso 1259, haciendo converger a ambas figuras en el mismo plano sintagmático, sino que también se expresa paradigmáticamente a través de la función poética que se establece mediante la rima entre "époux" y "courroux" - para pedir su ayuda. No obstante, esta acaba siendo innecesaria, puesto que es la misma Phèdre quien emite la sentencia del juicio: "Le crime de la sœur pase celui des frères" ["con su crimen la hermana supera a los hermanos"] (1262) y, en consecuencia, Aricie es condenada.

Más allá de la evidente semántica de la pasión violenta y los celos que domina en esta parte -aparecen términos y expresiones como "fureur" ["furor"], "jalouse rage" ["celosa rabia"], "perdre" ["causar la muerte"], "sang odieux" ["estirpe odiosa"], "courroux" ["cólera"] o "jaloux transports" [“celosos transportes"]-, el odio hacia Aricie se expresa a través múltiples

9 Christian Surber estudia detalladamente el fenómeno de la rima en el teatro raciniano y señala diversos ejemplos de asociaciones semánticas logradas mediante la rima, entre los que se encuentran precisamente los binomios épouse-jalouse y époux-courroux (202). 
mecanismos. Por un lado, el discurso adquiere un tono especialmente negativo al suprimir la ambivalencia inherente al personaje de Phèdre, derivada de su genealogía -en palabras de Spitzer, "Phèdre, hija del dios de los Infiernos, atormentada por fuerzas oscuras, busca la luz, el Sol de su antepasado", lo que la convierte en un "oxímoron encarnado" (305-306) ${ }^{10}-$, como muestran los versos 1242-1243: "Je me cachais au jour, je fuyais la lumière. / La mort est le seul dieu que j'osais implorer" ["me ocultaba en la sombra, huía de la luz: / la Muerte es el único Dios a quien me atreví a implorar"]. Por otro lado, se pone el énfasis en la desgracia de Phèdre a través de la antítesis con la felicidad de Aricie e Hippolyte: mientras ella sufre, ellos se burlan de su furor y ultrajan su felicidad haciéndose promesas de amor. De hecho, esta es una de las principales funciones del personaje de Aricie, quien en palabras de Desnain sería "the distorting mirror (in that it gives us a shallow and false image of feminity) which magnifies Phèdre's failings" (42). Cabe destacar que la recreación de las escenas eróticas, recordadas o imaginadas (como en este caso), es una constante del teatro raciniano, que no en vano recurre a menudo a la figura de la hipotiposis, por medio de la cual la imagen sustituye a la cosa (Barthes 61), así como la palabra sustituye al acto. Además, como consecuencia del carácter performativo de la palabra, Phèdre trata de atenuar su dolor evitando verbalizar sus causas de forma explícita, usando un lenguaje oculto conformado principalmente por perífrasis -se refiere a Aricie con la expresión "un sang odieux" (1260) y a su amor por Hippolyte como "le crime de la sœur" (1262)-. Asimismo, debemos advertir que estos versos aluden también a la genealogía de Aricie - evocan crímenes de sus hermanos, que considera más leves que los suyos (ibid.)- y, de este modo, dejan entrever que su existencia, como la de Phèdre, está marcada ya por el crimen, reforzando así su culpabilidad.

\section{SEGUNDO JUICIO: EL NARCISISMO DE LA HEROÍNA TRÁGICA}

El estado de furor es interrumpido en el verso 1264, cuando Phèdre se pregunta: "Que fais-je ?” [“¿Qué hago?”]. Una nueva Phèdre dialoga con la anterior, sorprendiéndose de su conducta, pero sin distanciarse del todo de ella: "Moi jalouse !" [“¡Yo celosa!”] (1265). Phèdre sustituye a Enone y deviene su 
propia interlocutora, de modo que, como ocurre a lo largo de toda la obra, "nominative and objective, looker on and looked upon, spectator and spectacle, speaker and spoken are fused, however discomfortably, into one unseverable entity" (Barnett 36). Después de emitir la primera sentencia, Phèdre advierte las consecuencias fatales que podría tener su agresiva actitud y adopta una posición más racional, por lo que llega a preguntarse: "Où ma raison va-telle s’égarer ?”[“¿De qué modo mi razón se extravía?”] (1264), para admitir finalmente que sus crímenes "ont comblé la mesure" ["colman la medida"] (1269). No obstante, en el estado de alteración en que se encuentra Phèdre, su inconsciente no puede dejar de emerger, pues en su verborrea irrefrenable revela inevitablemente sus pensamientos más profundos. Así pues, en esta parte irrumpen de nuevo los impulsos violentos de Phèdre, dirigidos en este caso no a Aricie, sino a sí misma, de modo que el sadismo se transforma en un masoquismo que se manifiesta en el plano físico -las metáforas eróticas adquieren una dimensión sensual y dolorosa: Phèdre arde de pasión y sus propias palabras de odio le ponen los pelos de punta (1266-1268)- y en el psicológico, mediante el sentimiento de culpabilidad -aquí el lamento constante de Phèdre da a su discurso un tono elegíaco, como evidencian los versos 1273-1274: "Misérable ! et je vis ? et je soutiens la vue / De ce sacré soleil dont je suis descendue ?” [“¡Miserable! ¿Y aún vivo? ¿Sostengo la mirada / de ese sagrado sol del que soy descendiente?"]-.

En esta parte de la escena se mantiene el fondo judicial, pero con ciertas modificaciones: de la misma forma en que Phèdre deviene a un tiempo emisora y receptora, reúne también en sí misma los roles de denunciante, de acusada y de juez: es decir, ella misma confiesa y determina su culpabilidad. Admite explícitamente que sus crímenes son "l'inceste et l'imposture" ["el incesto y la impostura"], además del homicidio al que hace referencia cuando habla de sus "homicides mains" ["homicidas manos"] (1270-1271). La alusión al último crimen es una prueba más de la performatividad de la palabra, que deviene prácticamente una entelequia: el homicidio no se ha producido realmente, pero sí se ha verbalizado, y con esto es suficiente para que tome valor de realidad. Así pues, la confesión de sus crímenes y el contraste con "le sang innocent" ["la sangre inocente"] de Aricie (1272) -que antes era "[un] sang odieux" ["[una] sangre odiosa"]- contribuyen a resaltar aún más la culpabilidad de Phèdre.

La monopolización por parte de Phèdre tanto de la comunicación como del juicio son muestras del narcisismo característico del héroe raciniano: "todo lo que hay en el mundo parece venir a buscarlo personalmente, todo se deforma 
para no ser otra cosa que un alimento narcisista: Fedra cree que Hipólito ama al mundo entero excepto a ella" (Barthes 76). En consecuencia, Phèdre contempla el mundo como un lugar hostil fundado sobre un enfrentamiento entre el yo y el otro, donde no existe posibilidad alguna de conciliación de las partes bajo un nosotros, de modo que

el yo existe en ella sólo bajo una forma hinchada al punto del estallido, al punto de la división (en el monólogo, por ejemplo); el tú es la persona de la agresión sufrida y devuelta (¡Pérfido!); el él es la persona de la decepción, el momento en que se puede hablar del ser amado como de un objeto falsamente distante, antes de volverse contra él (el ingrato); el vos es la persona del decoro, de la confesión o del ataque encubierto (Señora); el se o el ellos designan, como hemos visto, una agresión difusa. Hay una persona que falta en la conjugación raciniana: el nos: el mundo raciniano está dividido de un modo implacable: el pronombre de la mediación le es desconocido (Barthes 78-79).

\section{TERCER JUICIO: PHÈDRE, UNA VÍCTIMA CULPABLE}

Aunque parezca que finalmente el texto señale a Phèdre como única culpable, su discurso toma un nuevo rumbo con la introducción de un nuevo factor: su genealogía. Por un lado, Phèdre habla de Helios y Zeus, sus abuelos materno y paterno respectivamente, que vigilan cada uno de sus pasos en vida (12731277). Por otro, menciona a su padre, Minos, que la vigilará en los Infiernos cuando muera. De esta forma, Phèdre expone el alcance de su desgracia, que va más allá de la muerte, pues ni tan solo entonces podrá ocultarse, de modo que la escapatoria es imposible. En consecuencia, la imagen que se nos ofrece de Phèdre ya no es la de una criminal incestuosa, sino la de una víctima de la fatalidad.

La introducción de Minos en el discurso refuerza la interpretación de la escena en forma de juicio, puesto que no solo desempeña simbólicamente el rol de juez, sino que es uno de los tres jueces de los Infiernos -es por esto también que aquí prolifera el léxico jurídico: Phèdre usa vocablos como "urne fatale" ("urna fatal"), "juge" ("juez"), "avouer" ("confesar"), "forfaits" ("crímenes"), "crimes" (“crímenes") y "bourreau" ("verdugo")-. Así pues, en el juicio simbólico que corresponde a esta parte del soliloquio Phèdre sigue siendo a la vez denunciante y acusada, pero Minos la sustituye como juez. 
Minos constituye la figura de la legalidad por antonomasia, ya que además de ser juez propiamente es el padre de Phèdre $y$, como tal, representa el orden de lo simbólico, la ley del significante, pues es él quien impone la primera ley reguladora de las relaciones sociales, esto es, el tabú del incesto (Orlando 35). Siguiendo el planteamiento de Barthes, la misma presencia del padre-ley conlleva una culpabilidad esencial del héroe:

La culpabilidad del héroe es una necesidad funcional: si el hombre es puro, Dios es impuro y el mundo se desmorona. Es pues necesario que el hombre obtenga su falta como un bien precioso. [...] Dios, la Sangre, el Padre, la Ley, en síntesis la Anterioridad se hace acusadora por esencia. Esta forma de culpabilidad absoluta no deja de recordar lo que en la política totalitaria se llama la culpabilidad objetiva: el mundo es un tribunal, si el acusado es inocente, el juez es culpable; así pues, el acusado carga con la falta del juez (86-87).

A diferencia de los juicios simbólicos previos, el castigo se ejerce ahora desde una identidad más concreta -el padre-juez Minos--, de modo que el masoquismo que ya podíamos intuir en Phèdre queda ahora completamente explicitado. Para ilustrar el paso de Phèdre del sadismo al masoquismo más explícito, podríamos poner en correspondencia las tres posiciones freudianas del deseo con las tres fases de su discurso. La primera posición es la sádica, que se formula mediante el enunciado "El padre pega al niño (que yo odio)" (Freud 182) y que podríamos asociar a la primera parte del soliloquio, puesto que Phèdre parece hallar placer en la fantasía de una hipotética violencia ejercida por Thésée -sustituto por desplazamiento del padre-sobre Aricie-la persona odiada-. Después, el enunciado evoluciona a "Yo soy azotado por el padre", que presenta un "indudable carácter masoquista" (Freud 183) y que correspondería a la tercera parte del soliloquio, puesto que es donde se perfilan más claramente las identidades de los dos agentes que intervienen en la fantasía -el padre propiamente, Minos, ejerce la violencia sobre el sujeto en cuestión, Phèdre- $y$, por tanto, donde el masoquismo se manifiesta más abiertamente. La última posición freudiana se acerca nuevamente al sadismo como consecuencia de la represión ejercida sobre la segunda fantasía, que suele ser completamente inconsciente, de modo que la identidad del sujeto y del objeto de la violencia devienen imprecisas (Freud 186-187) -en este sentido, el narcisismo que caracteriza el masoquismo en la segunda parte del soliloquio de Phèdre evidencia la incapacidad de concretar los agentes 
de la fantasía-. La inversión del orden del discurso de Phèdre en relación con el orden en que se suceden las fantasías eróticas pone de manifiesto que, para Phèdre, no se produce una represión que frene la emergencia de sus impulsos, sino todo lo contrario: a partir del impulso inicial de Enone, Phèdre comienza a expresarse de forma casi automática, dejando entrever cada vez con mayor claridad sus pulsiones.

Finalmente, retomando la estructura en forma de juicio, la sentencia es nuevamente emitida por Phèdre, pero es más compleja que las anteriores: "Je crois voir de ta main tomber l'urne terrible, / Je crois te voir, cherchant un supplice nouveau, / Toi-même, de ton sang devenir le bourreau. / Pardonne ! Un Dieu cruel a perdu ta famille" ["Creo ver la urna terrible cayendo de tus manos. / Creo verte, buscando un suplicio distinto, convertirte en verdugo de quien lleva tu sangre. / Perdona. Un dios cruel perdió a tu familia"] (12861289). Al principio, la imaginación del castigo ejercido por Minos desata la ira de Phèdre, que entonces se rebela y acusa a su padre de ser el verdugo de su propia estirpe. No obstante, en cuanto advierte la gravedad de sus palabras -pues para los "héroes dogmáticos" como Phèdre, la infidelidad, es decir, el enfrentamiento con el padre y el rechazo del linaje, es la única forma de romper la ley (Barthes 88 ) - rectifica y culpa a la diosa Venus, que pasa a ser entonces la verdadera responsable de su pulsión incestuosa. Recordemos que, por un lado, Venus quería vengarse de Helios por haber contado a Hefesto su relación con Ares, por lo que, igual que hizo que Pasífae se enamorase de un toro, infundió en Phèdre una pasión irracional por Hippolyte. Por otro lado, Venus quería vengarse también de este último por su rechazo a rendirle culto en favor de Artemisa. Phèdre aparece entonces como una víctima de la ira de la diosa como consecuencia no de los múltiples delitos que se atribuía a sí misma, sino de delitos ajenos. Sin embargo, no debemos olvidar que la culpabilización de Venus surge como una correctio que oculta una verdad expresada previamente de forma inconsciente, es decir, que la culpa es del padre, lo que entronca con una idea esencial del teatro raciniano: la ausencia del padre constituye el desorden, su retorno instituye la falta (Barthes 80).

La concreción que caracteriza a esta parte del discurso y que, como acabamos de argumentar, podemos relacionar con un estadio más primario de la fantasía masoquista, se revela también en la especificidad espaciotemporal del "juicio", ya que sabemos exactamente dónde y cuándo se producirá: en los Infiernos, después de la muerte de Phèdre. Además de concreto, este juicio se plantea como más factible, puesto que parece más cerca de su realización al ser Minos caracterizado como "bourreau" ("verdugo"), un nuevo rol que 
sustituye al de juez a la vez que degrada su figura, puesto que la introducción del verdugo implica pasar de la sentencia a su ejecución, superando por fin el plano de la palabra para entrar en el de la acción.

La dualidad inherente a Phèdre -recordemos el planteamiento de Spitzer, según el cual Phèdre oscila entre dos fuerzas distintas como consecuencia de sus orígenes: la luz proviene de Pasífae, descendiente de Helios, mientras que la oscuridad proviene de Minos (305-306)-y que domina también en toda la obra, no de forma dialéctica, sino paradójica (Barthes 89$)^{11}$, se ve plasmada en esta escena no solo mediante la oposición entre Phèdre y Enone -"Enone's 'œil vivant', basically pagan, existential, energetic, pragmatic, a life-oriented point of view, contrasts vivividly with Phèdre's 'œil mourant', essentially Jansenist, pessimistic guilt-ridden, lethargic, and moribund" (Braga 289)-, más evidente en el diálogo final, sino también mediante las tres dicotomías que corresponden a las tres partes del discurso analizadas. Al principio, la felicidad de los amantes se contrapone a la desgracia de la protagonista. Después, la inocencia de los primeros contrasta con la culpabilidad de la segunda. Finalmente, la dicotomía que marca la última parte es precisamente la de la luz y la oscuridad, que apela directamente a la esencia del ser de Phèdre -quizás porque es aquí donde Phèdre se expresa más abiertamente, libre de censuras, para defender su criterio y a la vez el de Racine: "no es del todo culpable, ni inocente del todo" (Racine, Fedra 149)-.

\section{CUARTO JUICIO: LA RELACIÓN DE FUERZA ENTRE PHÈDRE Y ENONE}

Después del discurso de Phèdre que hemos categorizado como soliloquio, aunque no lo sea propiamente, vuelve a hablar Enone. Si en sus intervenciones previas Enone se revelaba como el doble idéntico de Phèdre, ahora deviene su contrapartida; deja de ser un otro para ser "el" otro. Enone aparece para delegar nuevamente la responsabilidad del crimen en Phèdre $-\mathrm{y}$ no en los dioses, como había hecho ella para justificar su inocencia-, pero pretendiendo

11 En relación con el carácter dicotómico de Phèdre, Orlando desarrolla una interpretación de la obra a partir del concepto freudiano de la "negación" y advierte que los elementos fundamentales de la pieza hallan su verdadero significado en su contrapartida, en lo que ocultan, de modo que se definen por contraste con lo reprimido (67). 
no culparla por seguir sus instintos: "Regardez d'un autre œil une excusable erreur. / Vous aimez. On ne peut vaincre sa destinée. / [...] La faiblesse aux humains n'est que trop naturelle" ["Mirad con otros ojos un excusable error. / Amáis. No se puede derrotar al destino. / [...] Nada hay más humano que la debilidad"] (1296-1301). En este sentido, la imagen que proyecta aquí CEnone encaja a la perfección con la definición que hace Mauron del personaje: una subordinada sin escrúpulos, celestina y delatora, que encarna el deseo de crimen, de confesión y de castigo (158). Sin embargo, Phèdre advierte las consecuencias que le puede acarrear su intervención y retoma el lenguaje de la agresión que había usado al principio contra Aricie: la llama "monstre exécrable" ["monstruo execrable"] (1317), la acusa de haberla envenenado, de haberla conducido a la perdición avivando su pasión por Hippolyte y desea que el cielo le dé su merecido. En este sentido, podríamos decir que se produce un último juicio simbólico, mediante el cual Phèdre se exonera nuevamente de sus crímenes haciendo responsable de ellos a Enone, de modo que finalmente consigue mantener intacta la inocencia que había construido a lo largo de su discurso. En realidad, esta conversación entre Phèdre y Enone constituye una lucha por imponer sus respectivos discursos, que ilustra claramente la "relación de fuerza" que conforma la estructura esencial de la tragedia raciniana. En Phèdre, la victoria o la derrota no dependen de si se es realmente inocente o culpable de los crímenes en cuestión, sino de la capacidad por imponer el propio relato de los hechos y convertir la versión subjetiva en verdad absoluta, haciendo desaparecer por la fuerza cualquier alternativa.

\section{CONCLUSIONES: LA NEGATIVIDAD COMO FUNDAMENTO DE LA TRAGEDIA}

Como hemos podido comprobar, la estructura judicial del fragmento permite observar con mayor claridad la forma en que Phèdre pasa de la posición de atacante a la de culpable para postularse definitivamente como víctima. Hay numerosas pruebas que nos llevan a concluir que el rol de víctima que toma Phèdre en el tercer juicio prevalece sobre los demás. Como hemos apuntado, el tercer juicio es más preciso y factible que los anteriores y, además, es el único que no queda invalidado por un juicio posterior -la condena de Aricie era sustituida por la de la propia Phèdre y la de esta, finalmente, por su inocencia, en detrimento de la culpabilidad de Minos, Venus y Enone-, 
sino todo lo contrario, puesto que el cuarto juicio desarrollado en el diálogo final no hace más que insistir en la inocencia de Phèdre. No obstante, Phèdre en ningún momento niega haber cometido los crímenes que ella misma se atribuye -nunca deja de referirse a ellos como "crimes" -, sino que tan solo trata de justificar su conducta delegando la responsabilidad en agentes externos; dichos crímenes han sido verbalizados y, por ende, perpetrados, de modo que son irreversibles, pero pueden ser corregidos mediante un nuevo discurso.

En consecuencia, el soliloquio de Phèdre evoluciona hacia una mayor complejidad que a su vez implica un progresivo acercamiento hacia el verdadero efecto trágico de la obra. Me explico: limitándonos a la estructura de la escena, la tercera parte del soliloquio de Phèdre incorpora los elementos más distintivos de las dos anteriores -aparece el furor en los reproches contra Minos, así como el tono elegíaco en el lamento constante por su "pénible vie" ["penosa vida"] (1294)-. Asimismo, desde una perspectiva más general, ateniéndonos ahora a la concepción aristotélica de la tragedia, la unión de la culpabilidad y la inocencia tiene como efecto el temor y la piedad necesarios para la identificación con la heroína y, por ende, para el efecto catártico propio del género ${ }^{12}$, de modo que la escena se postula como un verdadero paradigma de la tragedia -al menos desde la perspectiva de la Poética de Aristóteles, sin duda predominante en el siglo XVII-.

No obstante, creemos que, para el lector contemporáneo, el verdadero valor de la escena analizada no reside tanto en su capacidad para comprender la esencia de lo trágico como en la forma en que se logra dicho efecto: mediante la negación, esto es, mediante la frustración de la confesión a la que se le presupone normalmente la función de desencadenar la tragedia. La verborrea de Phèdre revela un principio esencial de la obra: la confesión no puede evitarse, como mucho puede reprimirse para que después surja por otras vías. Phèdre se niega a confesar ante Thésée, pero el motivo que la lleva a tomar esta decisión -la relación de Hippolyte y Aricie- despierta en ella un furor que provoca la emergencia de la confesión reprimida en forma de un discurso pasional y delirante en el que acaba por desvelar muchas más verdades de las que un discurso deliberado y racional podría haber ofrecido. Si bien Phèdre

12 De hecho, Phèdre busca abiertamente provocar dicha identificación cuando le dice a Enone: "Prends pitié de ma jalouse rage" ["Apiádate de mi rabia celosa"] (1258), lo que, en cierto modo, podría ir dirigido al espectador, encarnado en la figura de la nodriza, en tanto que espectadora también del soliloquio de Phèdre. 
decide no confesar ante Thésée, acaba por hacerlo ante el espectador-lector. En esta relación entre la negatividad y la verdad es donde halla Phèdre su máxima actualidad, pues incide en una idea eminentemente contemporánea como es el conocimiento de la realidad a partir de la negatividad o, en palabras de Foucault, de la personalidad a partir del desdoblamiento, de la memoria a partir de la amnesia, del lenguaje a partir de la afasia y, en definitiva, de la verdad a partir de su desaparición (285).

\section{BIBLIOGRAFÍA}

Barnett, Richard-Laurent. "Infinite Regress: Expansions of Naught in Racine's Phèdre". L'Esprit Créateur 38, N¹, 1998, 35-45.

Barthes, Roland. Sobre Racine. Madrid, Siglo XXI Editores, 1992.

Braga, Thomas J. “Double Vision in Racine's Phèdre”. The French Review 64, N², 1990 , pp. 289-298.

Desnain, Véronique. "Les Faux Miroirs: The Good Woman/Bad Woman Dichotomy in Racine's Tragedies”. The Modern Language Review 96, N¹, 2001, pp. 38-46.

Dictionnaire Grand Robert de la langue française (4 $4^{\mathrm{a}}$ ed.). París, Dictionnaires Le Robert, 2007.

Foucault, Michel. Folie et déraison: histoire de la folie à l'âge classique. París: Union Générale d'Éditions, 1961.

FrAPPIER, LOUISE. "La topique de la fureur dans la tragédie française du XVIè siècle". Études françaises $36136, \mathrm{~N}^{\circ} 1,2000$, pp. 29-47.

Freud, Sigmund. “'Pegan a un niño'. Contribución al conocimiento de la génesis de las perversiones sexuales (1919)". Obras completas. Tomo 17. Buenos Aires, Amorrortu Editores, 1990, pp. 173-200.

GIRARD, RenÉ. Mentira romántica y verdad novelesca. Barcelona, Editorial Anagerama, 1985.

Laplanche, Jean y Jean-Bertrand Pontalis. Diccionario de psicoanálisis. Barcelona, Editorial Paidós, 2004.

Mathé, Roger y Alain Couprie. Phèdre. París, Hatier, 1993.

Mauron, Charles. L'Inconscient dans l'œuvre et la vie de Racine. Aix-en-Provence, Publications des annales de la faculté des lettres, 1957.

Moliner, María. Diccionario de uso del español (3 $3^{\text {a }}$ ed.). Madrid, Editorial Gredos, 2007.

NÁÑez, Emilio. "Introducción”. Andrómaca. Fedra. Jean Racine. Madrid, Ediciones Cátedra. 7-58.

Orlando, Francesco. Lecture freudienne de “Phèdre”. París, Annales Littéraires de l'Université de Besançon, 1986.

Pavis, Patrice. Diccionario del teatro. Barcelona, Editorial Paidós, 1998.

Piglia, Ricardo. "Los sujetos trágicos (Literatura y psicoanálisis)". Formas breves. Barcelona, Anagrama, 2000, pp. 57-68. 
Racine, Jean. "Phèdre”. Euvres complètes. París, Éditions du Seuil, 1962, pp. 246-264. "Fedra". Andrómaca. Fedra. Madrid, Ediciones Cátedra, 1985, pp. 147-221.

Spitzer, Leo. "L'effet de sourdine dans le style classique: Racine". Études de style. SaintAmand, Éditions Gallimard, 1970, pp. 208-335.

Surber, Christian. Parole, personnage et référence dans le théâtre de Jean Racine. Génova, Librairie Droz, 1992. 